\title{
perifèria
}

Número 18(2), diciembre 2013

http://revistes.uab.cat/periferia

\section{Nomadisme dels pobles gitanos? Formació en situ amb estudiants del segon cicle a Romania}

\author{
Bálint-Ábel Bereményi, Alba Castellsagué Bonada \\ Universitat Autònoma de Barcelona - Departament d'Antropologia Social i Cultural ${ }^{1}$
}

\section{Resumen}

Existeix un ampli debat sobre la pràctica de nomadisme històric i contemporani als estats europeus. El que ens ocupa però, no és la tradició nòmada de diversos grups gitanos, ni les manifestacions o processos contemporanis de mobilitat, sinó més aviat la "nomadització de la cultura gitana" i alhora la tendència d'etnicització (o racialització) del nomadisme. A partir de tres casos i una primera exploració de la literatura sobre la història de la politització del terme i la pràctica del "nomadisme", tractarem de reinterpretar per què es perpetua l'associació automàtica dels gitanos amb el nomadisme, tant en els discursos populars com oficials i institucionals.

\begin{abstract}
There has been much debate about the practice of historic and contemporary nomadism in different European states. However, in this article our concern is not with the 'nomadic tradition of Roma groups' or with contemporary experiences of mobility, but rather we argue that there is a "nomadization of the Roma culture" and a parallel trend that ethnicizes (racializes) nomadism. Drawing on three cases, taken from other pieces of research, and an initial exploration of the literature on the historical politicization of the notion and practice of "nomadism", we intend to unveil the forces that perpetuate the automatic association of Roma with nomadic ways of life, in popular discourses as well as in official and institutional rhetorics.
\end{abstract}

\section{Prefaci}

Aquest text representa una breu reflexió que un grup d'estudiants d'antropologia de la UAB ha pogut desenvolupar sobre el concepte central d'aquest dossier: el nomadisme. Set estudiants ${ }^{2}$ han tingut I'oportunitat de participar en un projecte europeu: Programa Intensiu Erasmus "Roma Rights and Discrimination -

\footnotetext{
${ }^{1}$ Enviar correspondència a: abel.beremenyi@uab.cat

${ }^{2}$ Concretament: Alba Castellsagué, Paula Ferrer, Marina Girona, Patrícia López, Cristina Oliveros, Nicolás Piñeiro, Núria Rovira
} 


\section{perifèria}

Número 18(2), diciembre 2013

http://revistes.uab.cat/periferia

Approaches of a Right Based Social Work"3, amb la coordinació de Bálint Ábel Bereményi, professor del Departament d'Antropologia. En el marc del programa, les i els estudiants inicialment van cursar una fase preparativa de tres mesos implicant-se en la revisió de la literatura seleccionada, en la realització d'unes exploracions etnogràfiques $\mathrm{i}$ discutint els resultats en seminaris. Posteriorment, a Cluj-Napoca (Romania), van participar en set grups temàtics, juntament amb altres estudiants -en total 42- de set universitats europees. Entre els avantatges dels programes d'aquest tipus caldria subratllar-ne dues. Primerament, el fet que el tema central es pot discutir "en situ", directament connectat amb situacions empíriques rellevants, és indiscutiblement imprescindible en la formació dels futurs

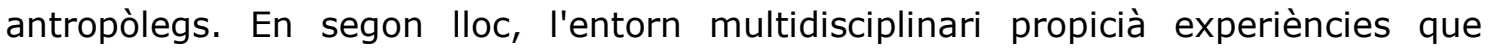
evidenciaven les àmplies diferències entre les reflexions i la interpretació de les realitats socials segons les disciplines allà representades (treball i educació social, pedagogia, magisteri, antropologia i sociologia). Com a tercera fase del programa, el grup tenia el compromís de presentar alguns resultats del procés d'aprenentatge plasmant l'experiència en productes concrets. Arran de la nostra participació en les jornades transdisciplinars de Primavera Nòmada ${ }^{4}$, hem tornat a organitzar els seminaris de treball i de reflexió, per tal de plasmar els aprenentatges concrets del programa i les lectures comunes rellevants en una presentació sobre les causes i condicions subjacents de les desigualtats observades, a través del prisma del "nomadisme com a estigma històricament i ideològicament construït". Així doncs, fem les següents reflexions basant-nos tant en la formació bàsica antropològica com en un projecte "d'aprenentatge en situ" intensiu i enriquidor, que trobem fonamental per complementar la primera.

\section{Introducció}

Existeix un ampli debat sobre la pràctica de nomadisme històric i contemporani als estats europeus. Molts són els grups de referència que, al menys una part de les

\footnotetext{
${ }^{3}$ Lifelong Learning Programme. Erasmus Intensive Programme (IP) 2012. Education and Culture DG [Reg Num: 2DF2B77B-13B0-43EC-96AC-9625D63C2C0F]

4 Jornades organitzades pel Col·lectiu "Estrat Crític" i els departaments de Prehistòria, Art i Musicologia i Antropologia Social i Cultural, de la UAB, el 13-16 de maig del 2013
} 


\section{perifèria}

Número 18(2), diciembre 2013

http://revistes.uab.cat/periferia

seves activitats de subsistència els vinculaven al nomadisme, sobre tot al nomadisme comercial (Frigolé 2005, García-Egocheaga 2003) o pastoral (Miralles i Sabadell, Tutusaus 2005). En aquest text, però, el que ens ocupa no és la tradició nòmada dels grups gitanos, ni les manifestacions o processos contemporanis de mobilitat, sinó més aviat la "nomadització de la cultura gitana" i alhora la tendència d'etnicització (o sovint la racialització) del nomadisme. Amb altres paraules, volem contextualitzar i comprendre com atribuïm - atrapats en la dicotomia "nòmade sedentari" (Deleuze, Guattari 1986, MacLaughlin 1999a) - el nomadisme als gitanos, com un tret ètnic o racial per explicar processos migratoris, en lloc d'explorar-ne "les raons reals incitadores i dissuasives econòmiques i polítiques" (Acton 2010:8), no només en discursos públics, sinó també en la legislació de països democràtics de la Unió Europea. El nomadisme actualment i històrica té associacions diverses des de la metaforització de la condició postmoderna (Smith, Katz 1993, Kabachnik 2010) fins l'estigmatització com a amenaça a la societat sedentària (MacLaughlin 1999a, Kabachnik 2010, McVeigh 1997, 1999b, Richardson 2006).

Queda fora del pensament antropològic suposar que tots els gitanos del continent europeu guarden històricament com a marcador d'identitat significatiu el nomadisme. De fet, la (re)construcció identitària dels gitanos i la "politització de la identitat 'roma'", o els intents contemporanis "d'europaització dels gitanos" no són fenòmens separables. També és cert, que la "reconstrucció de la història dels gitanos dependrà molt de la construcció d'intentitat" (Kovats 2013). En aquesta línia, trobem argumentacions polítiques (tant de polítics com d'organitzacions roma i pro-roma) en el sentit que a la identitat roma li manca base geogràfica, ja que és un poble sense "país mare" (pàtria) i per tant necessiten organitzacions transnacionals i intervencions internacionals que corresponen a l'estereotip tradicional dels nòmades viatgers (Kovats 2013:106). És a dir, el nomadisme no només s'ha etnicitzat a través de les representacions de la població sedentària, sinó també s'ha assumit per una part de les poblacions gitanes com a element identitari, malgrat el fet que la majoria d'ells (Acton 2010) mai no ha tingut cap experiència semblant.

En aquest text, doncs, proposem fer una primera aproximació a com el nomadisme constitueix, més que una pràctica, un element fonamental dels discursos i 


\section{perifèria}

Número 18(2), diciembre 2013

http://revistes.uab.cat/periferia

sentiments anti-gitanos, i com legitima accions xenòfobes improvisades o sovint oficials de l'administració pública. Les reflexions es basen en la revisió de la literatura, les discussions fetes en les tres fases del programa, i en les aproximacions etnogràfiques que els $\mathrm{i}$ les estudiants van fer amb persones i organitzacions gitanes i pro-gitanes tant a l'Estat espanyol com a Romania.

Primerament mirarem la "nomadització de la cultura gitana", és a dir, els discursos i representacions que es fan sobre els gitanos atribuint-los el nomadisme com a tret naturalment propi. En segon Iloc, esmentarem tres casos empírics de la literatura sociològica i antropològica per a il-lustrar els anteriors arguments. En tercer lloc, farem una breu revisió sobre la percepció del nomadisme com a pràctica no desitjada i alhora estigmatitzada i com el sedentarisme es transforma en una ideologia, que tancarem amb unes breus conclusions, tant sobre la relació entre nomadisme i gitanos europeus, com sobre la necessitat de proposar experiències semblants pels estudiants d'antropologia, en què la formació bàsica de la carrera pren un sentit veritable abans de la professionalització.

\section{1) Gitanos com a nòmades - discursos i representació}

La construcció de la història dels gitanos i els debats al seu voltant és producte d'intel-lectuals no gitanos (tret algunes excepcions). La "teorització" d'uns grups de comerciants vagabunds com a grup ètnic coincideix amb el procés de construcció dels estats nació i la cerca dels orígens dels pobles europeus. El primer estudi sobre gitanos amb gran influència i de llarga durada va ser el llibre de H. Grellmann (1783). Seguint N. Saul aquesta obra significa "una expressió de la tradició orientalista particular d'Alemanya" (Saul 2007:6), segons la qual, els gitanos representen un Naturvolk pre-civilitzat, infantilitzat, analfabets destacant romànticament la seva bellesa natural, però també alhora els seus defectes intel-lectuals significatius. Les "teories" sobre l'origen indià, probablement d'una casta baixa, i la seva necessitat innata de viatjar (Grellmann a Saul 2007:6-7) son dos elements fonamentals que han sobreviscut i/o reproduït fins l'actualitat. En l'obra de Grellmann i en altres sobre gitanos de l'època, la dicotomia nòmade sedentari s'aprofita al màxim en introduir la seva història, interpretant la transició del primer al segon com quelcom desitjable, inevitable i propi de la modernitat. Sovint es presenta la "cultura gitana" començant amb el seu llarg i dificultós viatge 


\section{perifèria}

Número 18(2), diciembre 2013

http://revistes.uab.cat/periferia

des de la Índia fins la Península Ibèrica. En aquestes presentacions, d'una banda els gitanos acostumen a fer-se conèixer com a estrangers que involuntàriament han format part de la societat on viuen, i de l'altra s'associen amb el propi viatge transnacional, amb l'aparentment continu nomadisme. El nomadisme s'ha utilitzat, fonamentalment, per una doble representació de la cultura gitana: la visió romàntica, exòtica (MacLaughlin 1999a) i metafòrica que es confronta amb una imatge criminalitzadora del grup (Bordigoni 2004, Scott 1998 a Vanderbeck 2005). Les dues visions, però, són difícilment separables en la representació pública. Aquestes representacions públiques també es plasmen en les polítiques específiques dirigides a la població gitana, en entorns molt diferents, com ho veurem en casos de Romania Itàlia i França.

\section{2) Casos empírics estudiats}

Per tal d'il-lustrar els arguments anteriors, a continuació proposem descriure tres casos concrets. El primer d'ells, conegut directament pels estudiants a través del Programa Intensiu Erasmus, correspon a la visita a un lloc d'extrema marginació urbana i violació de drets humans a la ciutat de Cluj Napoca (Romania). Tot i que no formava part del currículum del programa, resultà determinant en termes d'impacte i posteriors intents d'interpretació. Els altres dos casos sorgeixen de la recerca sociològica - antropològica.

\section{Romania - desnonaments al costat de l'abocador}

Pata Rât és un assentament situat en un abocador als afores de la ciutat de ClujNapoca, Romania, que recull diverses narratives i "incorpora processos històrics de canvis polítics, econòmics i socials que han col-locat els gitanos" (Raţ 2012). A Romania als gitanos sovint els identifiquen amb pràctiques de nomadisme. No obstant això, en aquest cas, prop del $42 \%$ de la població ha estat traslladada per les autoritats locals en circumstàncies diverses. El que coincidia en la majoria dels casos era la justificació que construïa un argument humiliant vinculant gent-perser-hi-moguda i un entorn estigmatitzat particular (Vincze 2012:3). Segons Vincze, la realitat de Pata Rât descriu fidelment les transformacions post-socialistes, en què la racialització dels gitanos és una tecnologia particular que racialitza processos de de-proletarització i de-universalització del ciutadans romanesos d'origen gitano. 


\section{perifèria}

Número 18(2), diciembre 2013

http://revistes.uab.cat/periferia

\section{Itàlia - "Campi nomadi" / "Aree Sosta"}

A Itàlia, als vuitanta, es va crear un únic terme administratiu per a identificar diversos subgrups gitanos amb històries de sedentarització històrica i de migració contemporània: 'nòmades'; però la majoria d'aquestes poblacions mai no ha practicat el nomadisme, per la qual cosa de vegades s'utilitza l'oxímoron "nòmades sedentaris" (Vitale 2010:1-2). En una publicació recent Picker (2011) fa conèixer com la legislació regional de la Toscana, al 1988, feia servir el discurs sobre nomadisme amb la intenció d'implementar intervencions per la "protecció de la minoria ètnica i lingüística gitana/Rom", sense esmentar el seu estatus d'estranger i migrant. Seguint aquesta lògica, arreu d'Itàlia es van construir "camps nòmades", com a mesura excepcional per una gent "caracteritzada per una forma de vida peculiar, nòmada" (Picker 2011:9). El "discurs nòmade" no desaparegué de la narrativa culturalista dels legisladors d'esquerres: a l'any 1995 la segona llei segueix problematitzant la vinculació de les persones amb el territori, reconeixent que els seus hàbits d'habitatge són peculiars, i diferents del de la resta de la societat; i pretén assegurar el dret a la forma de vida nòmada (Picker 2011:11). Sigona constata que la descripció dels Roma "com a nòmades no només serveix per segregar-los, sinó també per reforçar la idea popular que els Roma no són italians i no 'pertanyen' a Itàlia" (Sigona 2005:745).

\section{França - Gens de voyage éternelle}

El "nomadisme apareix com una categoria de l'acció pública que guia la major part de les polítiques públiques en relació amb aquesta població" (Bidet 2010:20). L'administració francesa té dificultats històriques de com definir aquests grups, popularment coneguts com a gitanos, bohemis, etc. que en certes èpoques es comparaven amb altres grups de vagabunds, una generalització que tenia implicacions serioses com que la vagància s'incloïa en la llei criminal i al llarg dels s. XVIII - XIX la criminalització s'acompanyà amb la definició de nomadisme com a patologia per tractar. Al 1912, com a intent de normalització es creà la categoria administrativa de "nòmade", registrada a través d'unes cartes específiques d'intentitat amb dades antropomòrfiques. Al 1969 es crea un nou "document de circulació" i la categoria "nòmade" se substitueix per la de "persones sense domicili ni residència fixa". Finalment, cal comentar la llei de 2000, que proposa la categoria 


\section{perifèria}

Número 18(2), diciembre 2013

http://revistes.uab.cat/periferia

de "gens du voyage", i prescriu l'establiment de "stopping places" a municipis majors de 50mil habitants. Alguns s'hi refereixen com a "eufemisme jurídic" (Lochak 2000 a Bidet 2010), ja que a França les minories no es reconeixen com a tal. Bidet afirma que parlant de "gens du voyage" tothom associa als gitanos, i d'aquesta manera la categoria perpetua la imatge del "gitano nòmade" (Bidet 2010:23).

En el següent apartat ampliarem la nostra visió cap a una discussió més general sobre el nomadisme, essencialment europea.

\section{3) Nomadisme - mobilitat: entre metàfora i estigma}

Thomas Acton descriu nomadisme com a "explotació recurrent d'oportunitats econòmiques espacialment i temporal discontinues" (Acton 2010:6). En principi, el sedentarisme és més eficient perquè elimina les despeses de viatge, però si al mateix Iloc no es donen oportunitats continues de treball productiu llavors la mobilitat és necessària. Aquesta aproximació al nomadisme, però, no té en compte les fronteres borroses entre les dues formes d'explotació econòmica, la sedentària i la nòmada, en temps i en espai. Les construccions contemporànies dels nòmades remunten a una llarga història d'establiment de por respecte als viatgers pobres (McVeigh 1997:8). En termes de MacLaughlin (1999a) la "geografia històrica de la intolerància" vers als nòmades s'origina del segle XVI, el començament de la Modernitat, al segle en què el pensament s'emmarca en binomis, categories mútuament excloents com a humà-animal, corporal-espiritual, o nòmade-sedentari (1999a). MacLaughlin (1999b) ubica l'exclusió més vehement del nomadisme per l'estat al segle XIX, i ho explica amb la confluència de les ideologies de darwinisme social i del nacionalisme burgès. La "denigració dels pobles viatgers era central en les teories d'evolució del desenvolupament social" (MacLaughlin 1999b:129). Els canvis en la consideració de la propietat, és a dir, del privat i del comú són fonamentals per comprendre l'actitud vers la dicotomia sedentarisme- nomadisme. A més a més, cal recordar la idiosincràsia de la ciutadania moderna, que sorgeix d'una cada cop més alta cohesió social, que atorga residència fixa als membres i posteriorment reconeix la seva ciutadania, fet que incrementa la diferència de poder entre membres/ciutadans i nouvinguts/estrangers (MacLaughlin 1999b:141). Alliberant el concepte del seu 


\section{perifèria}

Número 18(2), diciembre 2013

http://revistes.uab.cat/periferia

contingut ideològic històricament atribuït, podem comprendre el "nomadisme més que una alternativa a la vida moderna, com a una forma moderna de vida alternativa" (McVeigh 1997:15). El rebuig de les nocions de territorialitat i propietat diferenciada de l'espai ofereix una perspectiva alternativa de la civilització, la història i construcció normativa de la societat i l'estat (Deleuze i Guattar 1998 a Greenfields 2008).

\section{De la mobilitat a les mobilitats}

La mobilitat com a fenomen social conviu, es conjuga i interacciona amb d'altres eixos i trets d'identificació, categorització i desigualtat. "La mobilitat és quelcom més que moviment en general, ja que implica també totes les dimensions socials i culturals" (Creswell 2006 a Bærenholdt 2013:21). Així doncs, la mobilitat entra en diàleg amb altres característiques dels grups i individus, com són l'edat, el gènere, la classe social i l'ètnia.

Pel que fa a les relacions de poder i desigualtats de classe, el "sedentarisme" és el discurs que s'ha identificat amb la ideologia de la modernitat i la classe dominant, que reprodueix i legitima les nocions capitalistes de propietat i control i, sens dubte, el nomadisme desafia les relacions de propietat capitalista (McVeigh 1997). No obstant això, són diversos els autors que han parlat de la valoració social positiva de la mobilitat cosmopolita (Bærenholdt 2013, Hannerz 1997, Canzler, Kaufmann et al. 2008), quan aquesta es vincula a la llibertat i emancipació, com per exemple el mateix Programa Intensiu d'Erasmus en què hem participat. La jerarquització de la mobilitat fa que es valori de manera desigual el sedentarisme o el nomadisme, en funció d'altres eixos d'anàlisi, en aquest cas, la classe social. Alguns autors (Baumann 1999) afirmen que la mobilitat obliga a revisar la mateixa noció de classe i cal tenir-la en compte com un factor més d'estratificació social.

Des del punt de vista de l'etnicitat, investigadors com Mc Veigh (1997) o Bordigoni (2004) utilitzen la distinció d'un nomadisme ètnic, que provoca una reacció específica en establir relacions amb les ideologies i formes de vida sedentàries, com el racisme i les implicacions genocides. Altres, com Vincze (2012), prefereixen utilitzar el concepte de "racialització de l'exclusió social", quan es tracten les relacions entre grups en base a les seves diferències percebudes com a innates $i$ inamovibles, i no en base a les desigualtats; que tanmateix poden desembocar en 


\section{perifèria}

Número 18(2), diciembre 2013

http://revistes.uab.cat/periferia

adaptacions temporals d'alta mobilitat interpretada com pròpia d'un grup ètnico"racial". Així doncs, veiem com la mobilitat i les categories de nomadisme i sedentarisme s'han construït ideològicament per legitimar un ordre social i són estructurades a través d'altres factors socials com la raça o la classe social (McVeigh 1997); i que ambdues poden ésser representades i practicades com a formes d'estratificació.

\section{4) Reflexions finals i conclusió}

A través de l'aproximació empírica breu i la seva contextualització social, econòmica i política mitjançant la revisió de la literatura, s'ha intentat reconsiderar críticament les narratives sobre l'origen i la història comú d'un grup ètnico-cultural i els suposats elements i trets culturals que els uneixen a nivell europeu. El qüestionament de l'ús acrític generalitzat del concepte "nomadisme", tan sovint utilitzat per descriure el passat i present d'aquest grup, ens ha dirigit l'atenció als fonaments ideològics del "sedentarisme" per legitimar canvis polítics i socials fonamentals del procés de construcció de l'estat modern, o estat nació, a partir del s.XVI. El fonament teòric del "sedentarisme" de segles passats, que suposava un trànsit inevitable i desitjat des de formes més mòbils cap a més sedentàries de vida, jerarquitzava com a inferior aquells que s'asseguraven la subsistència amb pràctiques productives que requerien mobilitat, tot ocultant que la transició no ha estat mai absoluta, ni irreversible. Actualment, la jerarquització amb l'etiquetatge popular i institucional de "nòmade" segueix vigent, però amb altres lògiques. Mentre la mobilitat ha esdevingut un element clau al món contemporani, amb totes les infraestructures físiques i virtuals, l'accés a diversos sistemes de mobilitat no està equitativament repartida. Per a alguns grups socials l'alta mobilitat serveix com a font de riquesa i prestigi, per uns altres pot ser font de discriminació, marginació i desprestigi. En breu, els casos de França i Itàlia ens demostren com els propis legisladors institucionalitzen el desprestigi i la marginació, així com la vigilància i la sanció, d'un tipus de mobilitat - i fins i tot un tipus de sedentarisme definit com a "nòmade". En canvi, hem comprès des de l'exploració empírica i les posteriors discussions amb experts, que la "(re-)nomadització" de "la cultura gitana" té com a context fonamental la transfromació post-socialista dels noranta, amb el desenvolupament d'un capitalisme neoliberal. 


\section{perifèria}

Número 18(2), diciembre 2013

http://revistes.uab.cat/periferia

Aquestes breus reflexions representen un producte de tot un procés de preparació $\mathrm{i}$ aprenentatge, en el marc d'un projecte de Programa Intensiu. D'acord amb els objectius del mateix programa, considerem que la "formació en situ" en contextos sociopolítics variats, hauria de formar part del pla d'estudis de tots els estudiants d'antropologia, com un element fonamental en la seva professionalització. Tal com en el nostre cas, el treball multidisciplinari és imprescindible, justament perquè els estudiants prenguin consciència de quines són les aportacions que l'antropologia pot fer, des de l'aproximació teòrica i metodològica, en l'anàlisi de les realitats socials, en contrast amb les altres disciplines.

\section{Bibliografia}

Acton, T. (2010). Theorising Mobility: Migration, Nomadism, and the Social Reconstruction of Ethnicity. N. SIGONA and R. ZETTER, eds. In: Romani Mobilities in Europe: Multidisciplinary Perspectives. International conference, 14-15 January 2010, Refugee Studies Centre, University of Oxford, pp. 5-10.

Bærenholdt, J.O. (2013). Governmobility: The Powers of Mobility. Mobilities, vol. 8, no 1 , pp. 20-34.

Baumann, Z. (1999). Turistas y vagabundos. In: Z. Baumann, ed, La globalización: consecuencias humanas. pp. 103-133.

Bidet, M. (2010). Will French Gypsies Always Stay Nomadic and out of the LawMaking Process? N. SIGONA and R. ZETTER, eds. In: Roma Mobilities in Europe. Multidisciplinary perspectives. International Conference., 14-15 January 2010, Refugee Studies Centre, University of Oxford, pp. 20.

Bordigoni, M. (2004). La discrimination instituée dans l'unicité citoyenne : le paradoxe de la France face à la présence tsigane. Trabalho apresentado na $26^{a}$. Reunião Brasileira de Antropologia, realizada entre os dias 01 e 04 de junho. Porto Seguro, Bahia, Brasil.

Canzler, W., Kaufmann, V. and Kesselring, S., eds, (2008). Tracing Mobilities: Towards a Cosmopolitan Perspective. Aldershot: Ashgate.

Deleuze, G. and Guattari, F. (1986). Nomadology: The War Machine. New York: Semiotext(e). 


\section{perifèria}

Número 18(2), diciembre 2013

http://revistes.uab.cat/periferia

Frigolé, J. (2005). Dones que anaven pel món: estudi etnogràfic de les trementinaires de la Vall de la Vansa i Tuixent (Alt Urgell). Barcelona: Departament de Cultura.

García-Egocheaga, J. (2003). Minorías malditas: la historia desconocida de otros pueblos de España. Barcelona: Susaeta Ediciones, SA.

Greenfields, M. (2008). Accommodation Needs of Gypsies/Travellers: New Approaches to Policy in England. Social Policy and Society, vol. 7, n 01, pp. 73-89.

Grellmann, H.M.G. (1783). Die Zigeuner, ein historischer Versuch über die Lebensart, Verfassung und Schicksale dieses Volkes in Europa, nebst ihrem Ursprunge. Dessau and Leipzig.

Hannerz, U. (1997). Transnational Connections: Culture, People, Places. London New York: Routledge.

Kabachnik, P. (2010). Place Invaders: Constructing The Nomadic Threat In England. Geographical Review, vol.100, nº 1, pp. 90-108.

Kovats, M. (2013). Integration and the Politicisation of Roma Identity. In: W. GUY, ed, From Victimhood to Citizenship. The Path of Roma Integration. A debate, Budapest: Kossuth Kiadó.

MacLaughlin, J. (1999a). The Gypsy as 'Other'in European Society: Towards a Political Geography of Hate. The European Legacy, vol.4, no 3, pp. 35-49.

MacLaughlin, J. (1999b). Nation-Building, Social Closure and Anti-Traveller Racism in Ireland. Sociology, vol. 33, no 1, pp. 129-151.

McVeigh, R. (1997). Theorising Sedentarism: The Roots of Anti-Nomadism. In: T. ACTON, ed, Gypsy Politics and Traveller Identity. Hatfield, UK: University of Hertfordshire Press Hatfield, pp. 7-25.

Miralles i Sabadell, F. and Tutusaus, J. (2005). Mil anys pels camins de l'herba:el llegat d'un món que s'acaba. El Papiol: Efadós.

Picker, G. (2011). Welcome 'In'. Left-Wing Tuscany and Romani Migrants (19872007). Journal of Modern Italian Studies, vol. 16, no 5, pp. 607-620. 


\section{perifèria}

Número 18(2), diciembre 2013

http://revistes.uab.cat/periferia

Rat, C. (, 2012. Research Report. Participatory Assessment of the Social Situation of the Pata-Rât and Cantonului area, Cluj-Napoca. Cluj-Napoca: UNDP.

Richardson, J., 2006. The Gypsy Debate: Can Discourse Control? Exeter: Imprint Academic.

Saul, N. (2007). Gypsies and Orientalism in German Literature and Anthropology Ofthe Long Nineteenth Century. London: Modern Humanities Research Association and Maney Publishing.

Sigona, N. (2005). Locating 'the Gypsy Problem'. The Roma in Italy: Stereotyping, Labelling and 'Nomad Camps'. Journal of Ethnic and Migration Studies, vol. 31, no 4, pp. 741-756.

Smith, N. and Katz, C. (1993). Grounding Metaphor: Towards a Spatialized Politics. Place and the Politics of Identity, pp. 67-83.

Vanderbeck, R.M. (2005). Anti-Nomadism, Institutions, and the Geographies of Childhood. Environment and Planning D: Society and Space, vol. 23, no 1, pp. 7194.

Vincze, E. (2012). Urban Landfill: A Space of Advanced Marginality. SPAREX.

Vitale, T. (2010). Rom e sinti in Italia: condizione sociale e linee di politica pubblica. 21. Osservatorio di politica internazionale. 